Boise State University

ScholarWorks

$11-1-2010$

\title{
Step Counts of Non-White Minority Children and Youth by Gender, Grade Level, Race/Ethnicity, and Mode of School Transportation
}

Tyler G. Johnson

Boise State University

Timothy A. Brusseau

College of Brockport

Paul W. Darst

Arizona State University Polytechnic

Pamela H. Kulinna

Arizona State University Polytechnic

Janel White-Taylor

Arizona State University Polytechnic 


\title{
Step Counts of Non-White Minority Children and Youth by Gender, Grade Level, Race/Ethnicity, and Mode of School Transportation
}

\author{
Tyler G. Johnson, Timothy A. Brusseau, Paul W. Darst, Pamela H. Kulinna, \\ and Janel White-Taylor
}

\begin{abstract}
Background: The purposes of this study were to describe and analyze the steps/d of nonwhite minority children and youth by gender, grade level, race/ethnicity, and mode of school transportation. A secondary purpose was to compare the steps/d of minority children and youth to their Caucasian grade-level counterparts. Methods: Participants were 547 minority youth grades 5 to 8 from 4 urban schools. Participants wore sealed pedometers for 6 consecutive week/school days. Three hundred and ten participants responded to a questionnaire concerning their mode of transportation to and from school. Results: Statistical analyses indicated a main effect for gender $(F(3,546)=13.50, P<.001)$ with no interaction. Boys $(12,589 \pm 3921)$ accumulated significantly more steps/d than girls $(9,539 \pm 3,135)$. Further analyses also revealed a significant main effect for mode of school transportation $(F(2,309)=15.97, P \leq .001)$. Walkers $(12,614 \pm 4169)$ obtained significantly more steps/d than car $(10,021 \pm 2856)$ or bus $(10,230 \pm 3666)$ transit users. Conclusions: Minority boys obtain similar steps/d as their Caucasian grade-level counterparts; minority girls obtain less steps/d than their Caucasian grade-level counterparts. Minority youth who actively commute are more likely to meet PA recommendations than nonactive commuters.
\end{abstract}

Keywords: pedometer, adolescents, children, physical activity

The pedometer is a popular physical activity (PA) surveillance tool and is frequently employed to determine how many steps/day children and youth obtain. ${ }^{1-6}$ Results from pedometer studies show girls and boys age 6 to 18 living in the US tend to accumulate 10,000 to 12,000 and 12,000 to 16,000 steps/d, respectively. ${ }^{1-6}$ Two common findings have emerged from this literature. First, boys typically amass more steps/d than girls at various age and grade levels, but these gender differences decline substantially with age.' Second, youth (ie, 13 to 18 years) tend to accumulate fewer steps/d than children (ie, 6 to 12 years). ${ }^{\prime}$ To date most participants in pedometer studies (conducted in the US) have been Caucasian children and youth living in suburban areas with minimal representation of minority children and youth living in inner-city/ urban areas (see Table 1).

Johnson is with the Dept of Kinesiology, Boise State University, Boise, ID. Brusseau is with the Dept of Physical Education and Sport, College of Brockport, Brockport, NY. Darst and Kulinna are with the Dept of Physical Education, Arizona State University Polytechnic, Mesa, AZ. White-Taylor is with the Dept of Educational Innovation and Teacher Preparation, Arizona State University Polytechnic, Mesa, AZ.
Active commuting (ie, walking, skateboarding, cycling) to and from school is a viable means for youth to accumulate step counts or obtain PA. A study of New Zealand youth has shown that youth who walked at least to or from school averaged 1700 to 2300 more steps/d than youth who rode in a car or bus. ${ }^{7}$ Studies with accelerometers have also demonstrated a marked increase in moderate to vigorous physical activity (MVPA) participation among children who actively commuted to and from school versus those who did not. ${ }^{8-10}$ However, prevalence rates of active commuting to and from school among US children and youth have decreased from $40.7 \%$ in $1969 \%$ to $12.9 \%$ in $2001 .{ }^{11}$ Previous research has shown that the prevalence of active commuting is greatest among boys, minorities, and children and youth living in inner-city/ urban areas. ${ }^{12-14}$ Still, relatively little is known about the prevalence of active commuting to and from school and its relationship to the pedometer-determined steps/d of inner-city minority children and youth.

The purposes of this study were to describe and analyze the steps/d of minority children and youth (ie, African American and Hispanic) by gender, ethnicity, grade level, and mode of school transportation. A secondary purpose was to compare the steps/d of minority children and youth (grades 5 to 8 ) to their Caucasian grade-level counterparts reported in a previous study. 


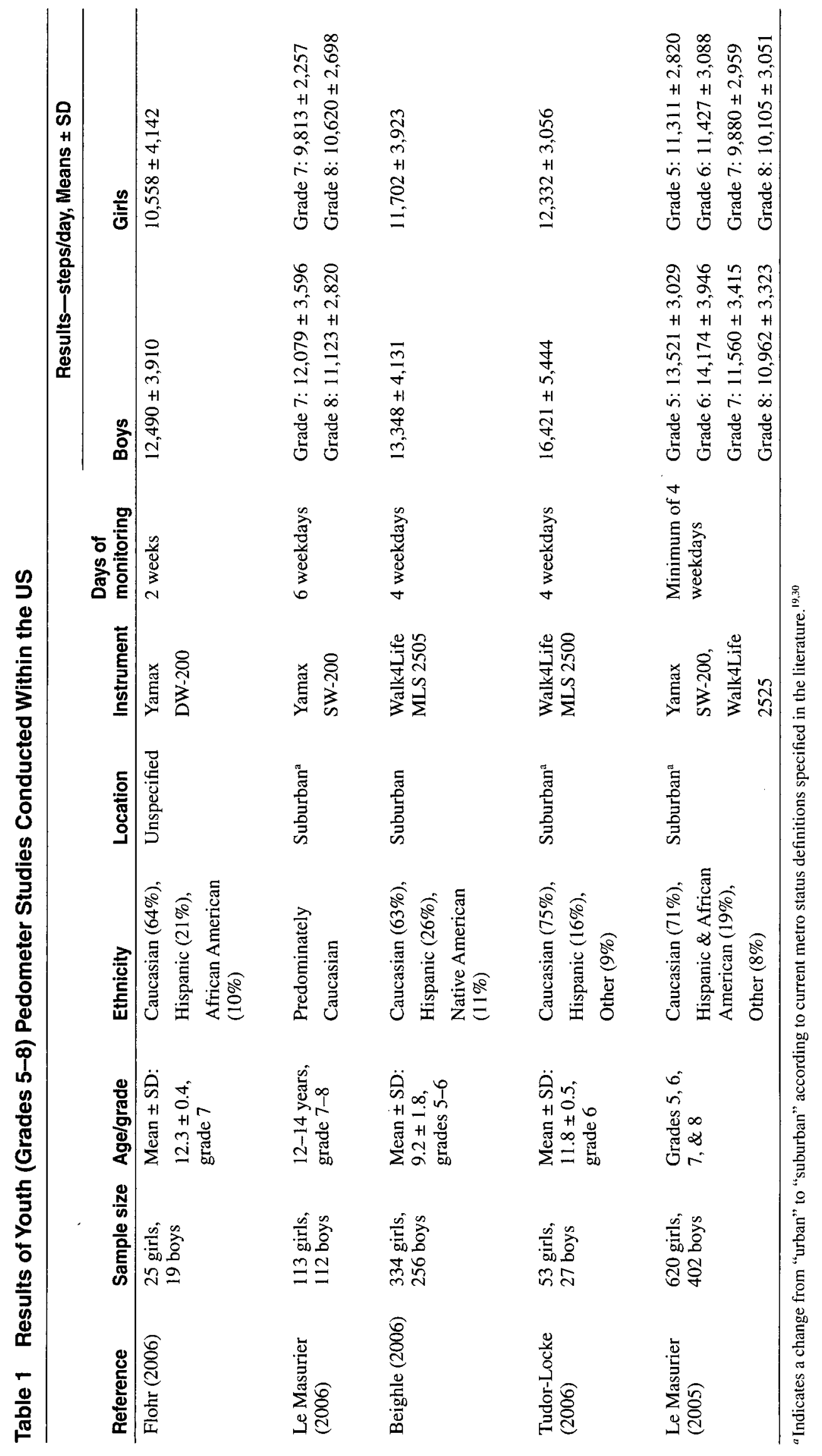




\section{Methods}

\section{Participants}

Participants included 687 inner-city children and youth ( $\mathrm{n}=386$ girls, $\mathrm{n}=301$ boys) grades 5 to 8 (age $11.8 \pm$ 1.2). The sample consisted of 53\% Hispanic, $43 \%$ African American, 3\% Caucasian, and 1\% Native American. Participants attended one of 4 inner-city K-8 schools located in 2 inner-city school districts. Schools were selected given their (a) inner-city location, (b) similarity in student demographics (ie, socioeconomic status and comparable African American and Hispanic populations), and (c) allocated time for Physical Education and activity breaks. All 4 schools offered Physical Education once a week for 45 minutes and a daily postlunch activity break for 30 minutes. Participants at each school chose to use postlunch activity breaks how they saw fit (ie, physical activity, socializing with friends, or study time).

IRB approval was obtained and principals and teachers' permission were granted before introducing participants to the study and before any data collection. After receiving instruction about the purpose(s) of the study and its requirements, each student who wanted to participate was given informed consent and written assent forms to take home and have signed by a parent/guardian. Only participants who returned signed informed consent and provided written assent were allowed to participate. Demographic information (ie, age, gender, grade, and ethnicity) for participants was obtained from school databases. The percentage of students attending each school participating in the free/reduced lunch program ranged from $80 \%$ to $99 \%$.

\section{Instruments}

Participants wore an MLS 2505 (Walk-4-Life, Inc., Plainfield, IL) pedometer that was sealed with a plastic tie positioned around the pedometer to prevent tampering with the display panel. Sealed pedometers have been used in a number of other research studies with children and youth. 1,2,5 The MLS 2505 has been shown to produce reliable and valid scores in pediatric populations. ${ }^{15,16}$

\section{Procedures}

Before data collection a trained research assistant provided a pedometer orientation to participants regarding what a pedometer is, how it works, and how to wear one properly. After these instructions, each participant received a pedometer. The assistant then guided the participants in locating an accurate place on the waist to wear the pedometer. A 20-count step test was performed by each participant with the pedometer attached above the right knee on the waist line. To perform the test, a participant (with the pedometer attached and reset to 0 ) would walk 20 steps verbally counting the steps as she or he walked. After completing 20 steps, the participant would stop walking and open her or his pedometer to discover how many steps the pedometer counted. If a 20-count step test yielded results on the pedometer greater than \pm 1 steps, the participant was instructed to reset the pedometer and place it on the right hip and complete the 20-count step test again. This process was repeated until all participants found an accurate place to wear the pedometer.

Participants wore their pedometers during school hours for 2 consecutive school days. These "practice days" were implemented to diminish potential novelty and reactivity effects before formal data collection began. Not being familiar with how a pedometer works may lead to reactivity, which is a concern when measuring PA participation. Even though researchers have suggested that reactivity may not be an issue when using sealed pedometers, the "practice days" were provided as extra protection against possible reactivity and novelty effects. ${ }^{17}$

Data were collected from November to April of the 2006 to 2007 school year. Data collection began on a Monday and continued for 6 consecutive school days, excluding weekends. A graduate student performed a pedometer calibration check the morning data collection began $^{18}$ and then sealed each pedometer. At a predetermined time, a graduate student would prompt participants to retrieve their assigned, numbered, and sealed pedometers from their class pedometer box and attach it to the waistband of their pants or shorts. Participants were instructed to wear the pedometer for the remainder of the day removing it only to sleep, shower (bath), or swim.

After waking in the morning, participants reattached their pedometers and wore them back to school. After participants had been wearing their pedometers for 24 hours, a graduate student would collect the pedometers and ask if any participants had failed to wear the pedometer for the entire day. If a participant indicated removal of the pedometer for more than 1 hour (excluding sleeping, swimming, or showering) during the previous day, the data were removed from the data set. In a separate room, research assistants unsealed each participant's pedometer, recorded the data, reset the display panel, and resealed the pedometer before giving it back to participants to wear for another day. The entire process described above was repeated for each of the 6 days of data collection.

Data regarding participants' mode of school transportation were collected at 2 of the 4 schools. At the conclusion of pedometer data collection, participants completed a brief questionnaire regarding their mode of school transportation. The questionnaire posed the following 2 questions: "what was your primary mode of transportation to school during our pedometer study" and "what was your primary mode of transportation from school during our pedometer study"? Participants were given 4 choices to choose from: walking, car, bus, or bicycle. Each participant's response was recorded. Ninety-two percent of participants reported using the same mode of transportation both to and from school. Eight percent reported using both walking and motorized transportation each day such as riding in a car or bus to school and walking home from school or vice versa. If a 
participant made at least 1 walking trip per day, he or she was placed in the walking group. This seemed to be the best approach due to the small percentage who reported both active and nonactive commuting each day. Only 2 participants reported cycling to and from school, so their data were excluded before data analyses.

\section{Data Treatment and Analyses}

Means \pm standard deviations were calculated for steps/d from the 6 days of monitoring. Participants with less than 4 days of data $(n=140)$ were excluded from the data set, which reduced the number of participants to 547 ( $\mathrm{n}=$ 311 girls, $n=236$ boys). The practice of including only participants with 4 or more days of data are similar to protocols in other large-scale youth pedometer studies. ${ }^{1}$ Internal consistency reliability measures (Cronbach's alpha) were calculated for all 6 days of monitoring to ascertain reliability of steps/d values. A $2 \times 2 \times 4$ ANOVA (gender $\times$ ethnicity $\times$ grade) was performed to determine whether significant differences in steps/d were present by gender, ethnicity, and grade level. Due to the smaller sample size $(n=310)$ separate analyses were performed for the mode of school transportation data. A 1-way ANOVA, controlling for gender, was conducted to discover significant differences in steps/d by mode of school transportation with corresponding post hoc tests. All statistical analyses were calculated using SPSS version 14.0 (SPSS, Inc., Chicago, IL.).

\section{Results}

Means \pm standard deviations for steps/d by gender, ethnicity, and grade level are presented in Table 2 and by gender and mode of school transportation in Table 3. The Cronbach alpha score $(95 \% \mathrm{CI})$ for days 1 thru 6 was 0.89 . Results from the $2 \times 2 \times 4$ ANOVA indicated a significant main effect for gender with no interaction $(F(3,546)=13.50, P<.001)$. Boys accumulated significantly more steps/d than girls overall and at each grade level. No significant differences in steps/d by ethnicity or grade level were found. Of the participants who reported their mode of school transportation, $32 \%$ walked, $31 \%$ rode in a car, and $37 \%$ rode the bus. Boys (37\%) had a higher prevalence of active commuting than girls (29\%). Results from the 1-way ANOVA, controlling for gender, suggested a main effect for mode of school transportation for both girls $(F(2,189)=8.78, P \leq .001)$ and boys $(F(2,119)=6.31, P \leq .01)$. Post hoc analyses revealed that minority children and youth who walked $(12,614 \pm 4169)$ obtained significantly more steps/d than those who rode in a car $(10,021 \pm 2856)$ or bus $(10,230 \pm 3666)$ to school.

Table 2 Steps/Day of Minority Children and Youth by Gender, Ethnicity, and Grade Level

\begin{tabular}{|c|c|c|c|c|}
\hline & \multicolumn{2}{|c|}{ Girls } & \multicolumn{2}{|c|}{ Boys } \\
\hline & $\mathbf{N}$ & Mean \pm SD & $\mathbf{N}$ & Mean \pm SD \\
\hline Gender: & 311 & $9,539 \pm 3,135$ & 236 & $12,589 \pm 3,921^{\mathrm{a}}$ \\
\hline \multicolumn{5}{|l|}{ Ethnicity } \\
\hline Hispanic & 155 & $9,747 \pm 3,006$ & 134 & $12,625 \pm 3,964^{\mathrm{a}}$ \\
\hline African American & 138 & $9,563 \pm 3,328$ & 98 & $12,618 \pm 3,907^{\mathrm{a}}$ \\
\hline \multicolumn{5}{|l|}{ Grade } \\
\hline 5 & 80 & $9,818 \pm 3,024$ & 74 & $12,933 \pm 3,703^{\mathrm{a}}$ \\
\hline 6 & 93 & $9,262 \pm 3,395$ & 61 & $11,848 \pm 4,210^{\mathrm{a}}$ \\
\hline 7 & 77 & $10,044 \pm 2,714$ & 48 & $12,988 \pm 4,272^{a}$ \\
\hline 8 & 61 & $8,956 \pm 3,292$ & 53 & $12,601 \pm 3,509^{a}$ \\
\hline
\end{tabular}

a Significantly different than girls at $P<.001$.

Note. Other ethnicities are not reported due to small numbers of participants.

Table 3 Steps/Day of Minority Girls and Boys by Mode of School Transportation

\begin{tabular}{llcccc}
\hline & \multicolumn{3}{c}{ Girls } & & \multicolumn{2}{c}{ Boys } \\
\cline { 2 - 5 } \cline { 5 - 6 } Mode & $\mathbf{N}$ & Mean \pm SD & & N & Mean \pm SD \\
\hline Walk & 55 & $11,319 \pm 3,715^{\mathrm{a}}$ & & 44 & $14,234 \pm 4,177^{\mathrm{a}}$ \\
Car & 60 & $9,145 \pm 2,395$ & & 37 & $11,442 \pm 2,999$ \\
Bus & 75 & $9,346 \pm 3,103$ & & 39 & $11,931 \pm 4,088$ \\
\hline
\end{tabular}

a Significantly different than other 2 groups at $P<.001$. 


\section{Discussion}

This study provides descriptive pedometer data for nonwhite minority boys and girls in grades 5 to 8 and highlights steps/d differences between those who engaged in active versus nonactive commuting to and from school. As shown in Table 1, most participants in previous pedometer studies conducted in the US have been Caucasian and have predominately included participants living in suburban areas. In addition, these studies have not investigated the prevalence of active commuting to and from school and how active commuting (ie, walking) is related to steps/d.

\section{Gender and Grade Level Differences}

In this study minority boys obtained approximately 3000 more steps/d than minority girls across all grade levels. Gender differences exceeded those reported in previous studies with predominately Caucasian participants. ${ }^{1-6}$ Larger gender differences in this study are likely a result of minority girls obtaining substantially less steps/d than their Caucasian grade-level counterparts.

Grade level steps/d differences were not found in this study. Previous research with children and youth has shown a substantial decline in steps/d with increasing age.' For example, participants in an upper elementary grade cluster (grades $4,5, \& 6$ ) obtained significantly more steps/d than participants in a junior high school grade cluster (grades 7, 8, \& 9).' A similar trend was expected in this study but was not observed. However, the low steps/d value for 8 th grade girls possibly indicates the beginning of the expected drop in steps/d with increasing age/grade level in minority girls.

\section{Race/Ethnic Differences}

There were virtually no steps/d differences between African American and Hispanic participants in this study (see Table 2). How do the steps/d of African American and Hispanic boys and girls compare with their Caucasian grade-level counterparts? Few published pedometer data exist comparing the steps/d of children and youth from various ethnicities because of the difficulty obtaining comparable numbers of participants in a single study. However, the data collection protocol and procedures employed in this study followed "empirically established methods of data collection" delineated in a previous study enabling a cross-study comparison of the steps/d of African American and Hispanic participants in this study and their Caucasian grade-level counterparts in another study (steps/d values for Caucasian children and youth grades 5 to 8 can be seen in Table 1 under Le Masurier).

The cross-study comparison reflects the following patterns: 1) minority girls obtain less steps/d than their Caucasian grade-level counterparts and 2) minority boys accumulate similar steps/d as their Caucasian gradelevel counterparts. Johnson and colleagues recently compared the steps/d of African American, Caucasian, and Hispanic 10- to 11-year-old boys and girls and found no significant differnces. ${ }^{19}$ However, Caucasian girls obtained approximately 400 and 1200 more steps/d than Hispanic and African American girls, respectively, following a pattern identified in the Youth Risk Behavior Surveillance System where a higher percentage of Caucasian girls ( $30.2 \%$ ) reported being physically active compared with Hispanic (26.5\%) and African American (21.3\%) girls. ${ }^{20}$ Data related to racial/ethnic differences among boys is mixed. ${ }^{19,21,22}$ Richmond and colleagues have recently argued that school location/environment (ie, urban/suburban/rural) is a stronger determinant of PA than race/ethnicity. ${ }^{22}$

The proposition that minority girls obtain less PA than Caucasian girls is well substantiated in the literature. Cross-sectional and prospective studies have connected adolescent female minorities, especially African Americans, with physical inactivity. ${ }^{23-26} \mathrm{Kimm}$ et $\mathrm{a}^{25}$ prospectively followed a group of 1213 African American and 1166 Caucasian girls for 10 years (up to age 18) to track leisure time PA. African American girls reported a $100 \%$ reduction in leisure time PA across the 10 years whereas Caucasian girls reported a $64 \%$ reduction. In another study, African American 8th grade girls reported significantly less vigorous and MVPA and more time spent watching television than 8 th grade Caucasian girls. ${ }^{23}$ Results from the current study provide objective data further emphasizing the need to assist adolescent female minorities in developing habits of regular PA.

\section{Mode of School Transportation Differences}

This study provides preliminary data regarding the relationship between mode of school transportation and pedometer-determined steps/d of minority children and youth. Prevalence rates of active commuting (32\%) in this study were higher than those reported nationally $(13 \%)^{11}$ supporting previous findings that minorities and those living in urban or inner-city areas engage in active commuting more often than whites and those living in suburban or rural areas. According to the National Household Transportation Survey, Hispanic (27.7\%) and African American (15.5\%) children and youth age 5 to 18 had the highest prevalence rates of active commuting compared with their Caucasian (9.4\%) age-related counterparts. ${ }^{14}$ However, race/ethnicity does not appear to be a primary determinant of active commuting to school. Recent research suggests that distance to school ( $\geq 1$ mile), ${ }^{14,27,28}$ annual household income $(\geq \$ 60,000$ per year) ${ }^{14,27}$ population density ( $\geq 25,000$ people per square mile $)^{14}$ and mixed land use ${ }^{27}$ increase the likelihood of active commuting to school among children and youth, regardless of race/ethnicity. Within this framework, the high prevalence of active commuting in this study is likely related to 1) participants living within walking distance to school (ie, 1 mile or less) and 2) low socioeconomics as evidenced by the high percentage of students $(80 \%$ to $99 \%$ ) receiving free/reduced lunch at 
each of the participating schools. Even though the area under investigation is considered inner-city/urban, the population density falls below the 25,000 people per square mile threshold. ${ }^{29}$

Does active commuting to school result in greater total accumulated PA? Boys and girls in this study who actively commuted averaged approximately 2700 and 2200 more steps/d than boys and girls who did not actively commute, respectively (see Table 3 ). These steps/d differences are strikingly similar to those recently reported for New Zealand youth age 15 to 18 years. ${ }^{7}$ Such large discrepancies between active and nonactive commuters suggests a positive influence of active commuting to school on total accumulated PA. However, it would seem that urban children and youth, due to their high prevalence of active commuting to school, would obtain more daily PA than children and youth living in suburban/ rural areas. Recent data has shown otherwise. ${ }^{19,30.31} \mathrm{John}$ son and colleagues recently investigated the accumulated steps/d of 10 to 11 year old children and found that children living in an urban area accrued approximately 1,400 and 1,100 less steps/d than suburban and rural children, respectively. ${ }^{19}$ In addition, self-report data has also shown that urban youth age 15 to 18 years report less physical activity and more sedentary behaviors than their suburban/rural age-related counterparts. ${ }^{30}$ Despite a higher prevalence of active commuting to school, urban youth tend to have limited access to physical activityrelated facilities, ${ }^{32}$ get fewer opportunities to participate in organized sport, ${ }^{33}$ and receive less time in physical education than suburban/rural youth. ${ }^{19.31}$ In terms of PA, what urban children and youth obtain from active commuting to school is minimal compared with what they lose in missed opportunities elsewhere.

Of the participants who actively commuted in this study, $66 \%$ of boys and $47 \%$ of girls met the President's Challenge recommendation of 13,000 and 11,000 steps/d for boys and girls, respectively. ${ }^{34}$ Of the participants who did not actively commute, $27 \%$ of boys and $24 \%$ of girls met the steps/d recommendation. Research has estimated that 1000 step counts derived from a pedometer is equivalent to approximately 10 minutes of activity time (ie, time spent moving in ambulatory PA). ${ }^{6}$ According to this suggestion, participants in this study who actively commuted averaged approximately 27 and 22 more minutes of activity time than nonactive commuters. Such a large difference indicates the importance of active commuting for children and youth living in inner-city/urban areas. With this in mind, finding ways to increase the proportion of children and youth who actively commute to and from school deserves continued attention.

\section{Strengths and Limitations}

The strengths of this study were as follows: 1) An objective measurement tool was used to assess the steps/d of nonwhite minority children and youth instead of commonly used self-report methods, 2) preliminary data made available regarding the relationship of active commuting to and from school and the steps/d of nonwhite minority children and youth living in the US, 3) the use of "empirically established methods of data collection" as described in a previous study so as to enable cross study comparisons, ${ }^{1}$ and 4) the large sample size.

This study was not without limitations. First, it was a cross-sectional study that included only participants in grades 5 to 8 . Future studies should employ prospective research designs and include inner-city minority youth from the remaining $\mathrm{K}-12$ grade levels so further racerelated step count comparisons can be made. Second, this study did not include sufficient Caucasian participants from the inner-city. Ninety-six percent of the students who attended the participating schools were either African American or Hispanic. Future studies should use schools where there is equal representation of participants of different races, although the difficulty of this has been mentioned. Third, data pertaining to distance traveled for participants who actively commuted to and from school was not obtained. Including such information would have enhanced our understanding of the role active commuting played in accumulated steps/d.

\section{Conclusions}

Within the limits of the design of this study the following conclusions were drawn: 1) nonwhite minority boys are as active as their Caucasian grade-level counterparts, 2) nonwhite minority girls are less active than their Caucasian grade-level counterparts, and 3) inner-city nonwhite minority children and youth who actively commute to and from school are more likely to meet national PA' guidelines than nonactive commuters. The latter emphasizes the need to increase the proportion of youth who actively commute. Although descriptive, this study offers objective PA data of nonwhite minority children and youth, whose inclusion has been limited in previous large-scale pedometer studies.

\section{References}

1. Le Masurier GC, Beighle A, Corbin CB, Darst PW, Morgan C, Pangrazi RP. Pedometer-determined physical activity levels of youth. J Phys Act Health. 2005;2:159-168.

2. Vincent SD, Pangrazi RP. An examination of the activity patterns of elementary school children. Pediatr Exerc Sci. 2002;14:432-441.

3. Flohr JA, Todd MK, Tudor-Locke C. Pedometer-assessed physical activity in young adolescents. Res $Q$ Exerc Sport. 2006;77:309-315.

4. Tudor-Locke C, Lee SM, Morgan CF, Beighle A, Pangrazi RP. Children's pedometer-determined physical activity during the segmented school day. Med Sci Sports Exerc. 2006;38:1732-1738.

5. Beighle A, Pangrazi RP. Measuring children's activity levels: the association between step-counts and activity time. J Phys Act Health. 2006;3:221-229.

6. Le Masurier GC, Corbin CB. Step counts among middle school students vary with aerobic fitness level. Res $Q$ Exerc Sport. 2006;77:14-22. 
7. Hohepa M, Schofield G, Kolt GS, Scragg R, Garrett N. Pedometer-determined physical activity levels of adolescents: differences by age, sex, time of week, and transportation mode to school. J Phys Act Health. 2008; (Suppl 1):S140-S152.

8. Cooper AR, Andersen LB, Wedderkopp N, Page AS, Froberg K. Physical activity levels of children who walk, cycle, or are driven to school. Am J Prev Med. 2005;29:179-184

9. Sirard JR, Riner WF, McIver KL, Pate RR. Physical activity and active commuting to elementary school. $\mathrm{Med} \mathrm{Sci}$ Sports Exerc. 2005;37:2062-2069.

10. Cooper AR, Page AS, Foster MS, Qahwaji MS. Commuting to school: are children who walk more physically active? Am J Prev Med. 2003;25:273-276.

11. McDonald NC. Active transportation to school: trends among US schoolchildren, 1969-2001. Am J Prev Med. 2007;32:509-516

12. Robertson-Wilson JE, Leatherdale ST, Wong SL. Socialecological correlates of active commuting to school among high school students. J Adolesc Health. 2008;42:486-495.

13. Evenson KR, Huston SL, McMillen BJ, Bors P, Ward DS. Statewide prevalence and correlates of walking and bicycling to school. Arch Pediatr Adolesc Med. 2003; 157:887-892.

14. McDonald NC. Critical factors for active transportation to school among low-income and minority students: Evidence from the 2001 National Household Travel Survey. Am J Prev Med. 2008;34:341-344.

15. Beets MW, Patton MM, Edwards S. The accuracy of pedometer steps and time during walking in children. Med Sci Sports Exerc. 2005;37:513-520.

16. Schneider PL, Crouter SE, Lukajic O, Bassett DR. Accuracy and reliability of 10 pedometers for measuring steps over a 400-m walk. Med Sci Sports Exerc. 2003;35:1779-1784.

17. Vincent SD, Pangrazi RP. Does reactivity exist in children when measuring activity levels with pedometers? Pediatr Exerc Sci. 2002;14:56-63.

18. Vincent SD, Sidman CL. Determining measurement error in digital pedometers. Meas Phys Educ Exerc Sci. 2003;7:19-24.

19. Johnson TG, Brusseau TA, Vincent-Graser S, Kulinna PK, Darst PW. Step counts of 10-11 year old children by ethnicity and metropolitan status. J Phys Act Health 2010;7:355-363.

20. Centers for Disease Control and Prevention. Youth risk behavior surveillance-United States, 2005. MMWR Morb Mortal Wkly Rep. 2006;55:1-112.

21. Sallis JF, McKenzie TL, Elder JP, et al. Sex and ethnic differences in children's physical activity: Discrepancies between self-report and objective measures. Pediatr Exerc Sci. 1998;10:277-284.

22. Richmond TK, Hayward RA, Gahagan S, Field AE, Heisler M. Can school income and racial/ethnic composition explain the racial/ethnic disparity in adolescent physical activity participation? Pediatrics. 2006;117:21582166.

23. Felton GM, Dowda M, Ward DS, Dishman RK, Trost SG, Saunders R. Differences in physical activity between black and white girls living in rural and urban areas. $J$ Sch Health. 2002;72:250-255.

24. Gordon-Larsen P, McMurray RG, Popkin BM. Adolescent physical activity and inactivity vary by ethnicity: the national longitudinal study of adolescent health. $J$ Pediatr. 1999;135:301-306.

25. Kimm SY, Glynn NW, Kriska AM, et al. Decline in physical activity in black girls and white girls during adolescence. $N$ Engl J Med. 2002;347:709-715.

26. Kimm SY, Glynn NW, Kriska AM, et al. Longitudinal changes in physical activity in a biracial cohort during adolescence. Med Sci Sports Exerc. 2000;32:1445-1454.

27. McMillan TE. The relative influence of urban form on a child's travel mode to school. Transp Res Part A. 2007;41:69-79.

28. Dellinger AM, Staunton CE. Barriers to children walking and bicycling to school-United States, 1999. MMWR Morb Mortal Wkly Rep. 2002;51:701-704.

29. US Census Bureau. 2000 US Census Population and Housing, Summary File 1 using American Fact Finder. http:// factfinder.census.gov. Accessed June 18, 2009.

30. Springer AE, Hoelscher DM, Kelder SH. Prevalence of physical activity and sedentary behaviors in US high school students by metropolitan status and geographic region. $J$ Phys Act Health. 2006;3:365-380.

31. Springer AE, Hoelscher DM, Castrucci B, Perez A, Kelder SH. Prevalence of physical activity and sedentary behaviors by metropolitan status in $4^{\text {th }}$-, $8^{\text {th }}$-, and 11 -grade students in Texas-2004-2005. Prev Chronic Dis. 2009;6(1) http://www.cdc.gov/pcd/issues/2009/jan/07_0252.htm Accessed June 19, 2009.

32. Powell LM, Slater S, Chaloupka FJ, Harper D. Availability of physical activity-related facilities and neighborhood demographic and socioeconomic characteristics: a national study. Am J Public Health. 2006;96:1676-1680.

33. Centers for Disease Control and Prevention. Physical activity levels among children ages 9-13 years, United States. MMWR Morb Mortal Wkly Rep. 2003;52:785-788.

34. US Department of Health and Human Services. The President's Challenge. http://www.presidentschallenge. org/index.aspx. Accessed June 19, 2009. 
Copyright of Journal of Physical Activity \& Health is the property of Human Kinetics Publishers, Inc. and its content may not be copied or emailed to multiple sites or posted to a listserv without the copyright holder's express written permission. However, users may print, download, or email articles for individual use. 